\title{
Trial Production of Porous Ceramics Filter Made from Sediments in Water Reservoirs for Sustainable Use of Surface Water Resource in Arid Land
}

\author{
Mitsuteru Irie, Sena Taga, Jamila Tarhouni, and Masayoshi Fuji
}

\begin{abstract}
Rapid sedimentation in water reservoirs in arid area is driving the sustainability of surface water resource into a corner. Dredging is one of expected and effective countermeasures to the sedimentation, but such maintenance works tend to be refused in the developing countries that gives a priority to economic growth. The authors proposed using the sediment as the raw materials for soil amendment, anti-allergy functional food and construction bricks, in order to cover the cost of dredging the sediment in reservoirs. The profits taken from these products were discussed for covering the dredging cost. However, neither uses satisfy the conditions of financial coverage for dredging. Some are not feasible, another cannot consume all the sediment yield in the country. In order to practice the exploitation of the sediment, a use for other purposes, especially for higher value-added products, should be proposed.
\end{abstract}

In this study, the production of the porous ceramics usable for water purification filter is discussed. The porous ceramics were prepared by gelcasting method. Detergent and synthetic resin is mixed with slurry. After foaming the detergent, the slurry is solidified rapidly by the resin to keep the matrix structure. This method has already been applied to pure materials such as alumina with low curing shrinkage rate in precedence studies. In this study, the sediment had higher shrinkage rate that causes cracking in drying process, so that more amount of resin was added. The mixing ratio of water, sediment and detergent, and mixing time were changed for the discussion about the variation of characteristics of the porous ceramics.

Porosity and permeability could be increased by the higher water contents and longer mixing time while the strength was reduced at these conditions.

Index Terms-Reservoir, sediment, exploitation, porpus ceramics.

\section{INTRODUCTION}

One of the most serious problems in water resource management, especially in arid and semiarid land such as Mediterranean countries, is sedimentation in reservoirs. Sediment accumulation in the reservoirs reduces the water storage capacity. The annual reduction rate of water storage capacity in North African countries reaches up to $0.5 \%$ in Morocco and Algeria, and $1 \%$ in Tunisia [1], [2]. In the most serious case, almost all of the storage capacity of the dam was

Manuscript received March 1, 2017; revised June 1, 2017. This work was supported in part by Ministry of Education, Science, Sports and Culture, Grant-in-Aid for 506 Scientific Research (A), 2014, 25257306.

M. Irie is with University of Miyazaki, Gakuen Kibanadai Nishi, Miyazaki, Japan (e-mail: irie.mitsuteru.p2@cc.miyazaki-u.ac.jp).

S. Taga is with TEC International Co., Ltd.

J. Tarhouni is with National Institute of Agronomy Tunis, Tunis.

M. Fuji is with Nagoya Institute of Technology, Japan. occupied by sediment.

The countermeasure to the sedimentation is imperative in these countries. Recent years, bypass for sediment discharge [3], [4] that can separate turbid flood water from inflow river and skip the reservoir water body to the downstream. However, special hydraulic structures are required from the beginning of construction planning. Another countermeasure is optimized gate control for density current venting [5], [6]. In the Mediterranean countries that have a rainy season in winter, inflow river water has higher density due to higher turbidity and lower temperature than the water body in the reservoir forms bottom density current [7]. The density current does not diffuse in the water body of reservoir and it can reach with less dilution of wash load at the outlet of the reservoir. Adequate opening of the gate can discharge the wash load to downstream without sedimentation in reservoirs. The gate control for the density current venting does not need specific facilities and is one of the reasonable counter measures to sedimentation, especially in developing countries that have limitation of budget for water resource management. However, the bypass and density current venting cannot recover storage capacity by the excavation of sediment while possible to reduce sedimentation in future.

Dredging settled sediment is most sure method to recover the storage capacity. However, it has not been carried out especially in developing countries because dredging is very costly. As a practical solution, the exploitation of the sediment for covering the dredging cost with profit of the products made from sediment was proposed [8]. Several options of exploitation exist, such as repairing material for embankment [9], soil amendment [10] and fulvic acid contained in sediment for functional food [11], [12].

On the other hand, the industries related to the ceramics such as construction bricks, pottery and tiles are the important sectors that cover the large part of the working population in Tunisia [13]. The raw materials, clay or silt are excavated from opencast site of limestone clay stratum. The opencast site give the negative impact on landscape and environment, risks of landslide, soil erosion, air pollution with dust etc. The authors proposed the exploitation of the sediment as raw material of the ceramics industries instead of that from open cast site [14], [15]. The sediment in reservoirs in Tunisia is fine silt. The first evaluation that the authors tried, including economical point of view was the production of construction bricks. The ceramics made from sediment performed enough strength for construction bricks. The exploitation of sediment as raw material for ceramics industries has been proven also in other areas [16]-[18]. From the economic point of view, the dredging cost (4.5 Tunisia Dinar $\left./ \mathrm{m}^{3}\right)$ is cheaper than the charge that the brick company 
pays for the open cast site (7.5 Tunisia Dinar $\left./ \mathrm{m}^{3}\right)$. However, it was estimated that the total annual yield of sediment from 20 large dams in Tunisia (10 million ton) is much larger than the consumption of clay in construction brick industry $(4.4$ million ton). Even though all the buildings in Tunisia are constructed with bricks, the excess supply will occur.

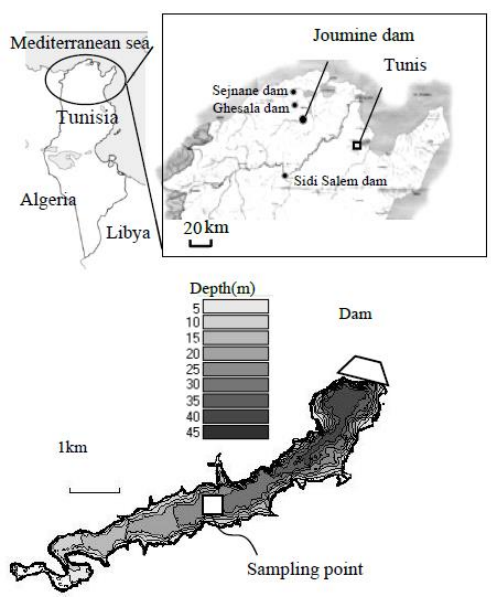

Fig. 1. Location of the reservoir that sediment sample was taken from.

This study proposes the exploitation of sediment for more value added use than construction brick. If consuming the remaining sediment that cannot be consumed in brick industry for more value added products, even with the required raw material resource demand, the possibility of covering dredging cost might be found. The target product is ceramics but functional one. Porous ceramics are used for filtration. In this study, preparation of porous ceramics made from sediment by gelcasting method was tried and the properties of the ceramics filter, such as porosity, permeability and pore size distribution, are evaluated.

\section{MATERIAL AND METHODS}

\section{A. Sediment Sampling}

Sediment samples were collected from the bed of Joumine reservoir in Tunisia by using an Ekman-berge bottom sampler (RIGO CO., LTD.). Joumine reservoir on the north area of Tunisia, $50 \mathrm{~km}$ from Tunis, was constructed in 1986 (Fig. 1). Its current storage capacity is 108.7 million $\mathrm{m}^{3}$. Sedimentation ratio of this reservoir is $10 \%$. The depths of the maximum water level at the sampling point was $20 \mathrm{~m}$. The thickness of sediment at this point is around $8 \mathrm{~m} \mathrm{[2].}$

The background of the construction of Joumine reservoir is related to the high salinity in Sidi Salem reservoir, the largest reservoir in Tunisia (storage capacity is 348 million $\mathrm{m}^{3}$ ). Salinity of Sidi Salem dam has 3\% of concentration [19] because its stream runs through drought and salt-accumulated land. This high salinity makes problem for irrigation, industrial and domestic use. Therefore, Tunisian Government constructed the new 3 reservoirs, Joumine, Ghesala, Sejnane which are located on the northern mountain, relative humid area for the dilution of water supply from Sidi Salem reservoir. From this background, it is possible to say that the salinity of Joumine reservoir is low. The precipitation and vegetation cover in its catchment area is high comparatively in Tunisia. Thus, from the point of view of sedimentation quantity in the reservoir, the load in this reservoir is lower than others located in the south of Tunisia, more arid regions.

Regarding the quality of sediment, physical and chemical properties of the sediment samples of the 4 reservoirs including Joumine reservoir have already been surveyed [12]. Particle size of the sediment samples are almost same among the 4 reservoirs but chemical property such as heavy metal content, TOC, CEC, Elemental composition of extracted fulvic acid etc. were not uniform. Except the ceramics made from the sediment sampled from the reservoir located in low-precipitation area, the ceramics samples show the enough strength for construction bricks [14]. Almost all of the reservoirs in Tunisia are located in relatively high precipitation area. So that, there is the enough representativeness of the sediment sample of Joumine reservoir for producing ceramics products. Table I shows basic property of the sediment. Chemical composition shown in Table II was investigated with portable X-Ray Fluorescence (Bruker S1-Turbo SD-LE) [20]. Relatively high content of Calcium is due to lime stone base rock in this region.

\begin{tabular}{cc}
\multicolumn{2}{c}{ TABLE I: PROPERTY OF THE SEDIMENT SAMPLE } \\
\hline Item & Value \\
& 2.714 \\
Soil particle density $\left(\mathrm{g} / \mathrm{cm}^{3}\right)$ & 74.9 \\
Liquid limit $(\%)$ & 22.6 \\
Plastic limit $(\%)$ & \\
\hline & \\
TABLE II: COMPOSITION ANALYSIS WITH X-RAY FLUORESCENCE \\
\hline Chemical Composition & Ratio $(\%)$ \\
& \\
$\mathrm{SiO}_{2}$ & 30.63 \\
$\mathrm{Al}_{2} \mathrm{O}_{3}$ & 12.17 \\
$\mathrm{Fe}_{2} \mathrm{O}_{3}$ & 5.28 \\
$\mathrm{CaO}^{\mathrm{MgO}}$ & 18.68 \\
$\mathrm{MgO}^{2}$ & 3.50 \\
\end{tabular}

\section{B. Preparation of Porous Ceramics by Gelcasting Method}

There are several kinds of method to prepare porous ceramics, such as burning out polymeric sponge impregnated with a ceramics slurry [21], solid-state sintering[22], sol-gel process[23], replication of polymer foams by impregnation[24] and gelcasting process [25]. In this study, gelcasting with epoxy resin was tried. The porous ceramics produced by this method has the characteristics of the less heterogeneous and less fault in green body. A process flow chart of gelcasting method with epoxy resin was shown in Fig. 2.

Sand (1/3 of dried sediment weight) was added to dried crashed sediment in order to regulate shrinkage that causes cracks on green body. Moisture content ratio ((water / the sediment-sand mixture solid)*100) was controlled to 70,80 , 90 and 100. Dispersant of $1 \mathrm{wt} \%$ of total solid-liquid weight was added. For the solidification resin, Sorbitol Polyglycidyl Ether (Denacol614B, Nagase Chemtex Cooporation) was added with the concentration of $10 \mathrm{wt} \%$. At the beginning of this preparation, the amount of added resin was $1 \mathrm{wt} \%$ referring in the previous study of gelcasting. However, due to the high shrinkage rate of the sediment sample, the green body could not keep the form without cracks. In order to harden wet-green body, the amount of resin was increased to $10 \mathrm{wt} \%$. 


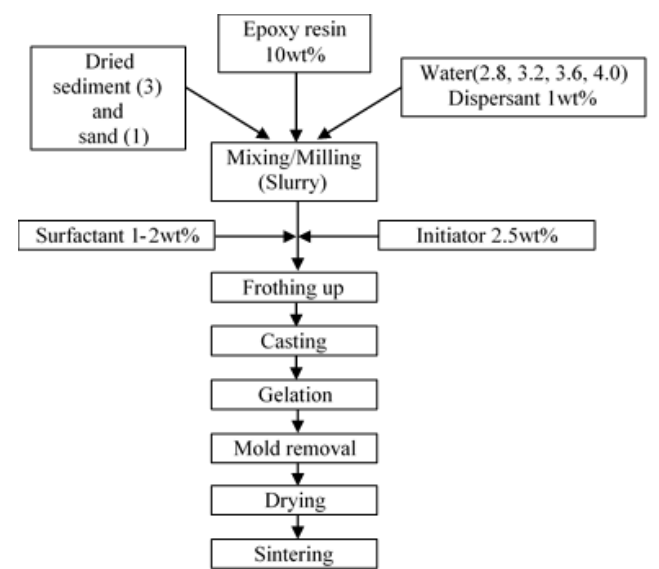

Fig. 2. Process flow chart of gelcasting method with epoxy resin.

After mixing the materials by ball-milling for 24 hours, Surfactant and Initiator were added. Then the slurry was frothed up. The time for frothing up was varied from 30 seconds to 120 seconds. In drying process, rapid drying make the gradient of moisture content from the surface to the center of green body. Shrinkage of the sediment depending on drying is so high that steep gradient of water content from the surface to center causes cracking. In order to prevent the cracking on green body, slow drying process was taken. The green body was kept in room temperature and wrapped with cellophane roughly. The wet-green body was placed in a small box with holes that makes gradual drying condition. It takes 15-20 days for wet-green body that is $40 \mathrm{~mm}$ in diameter, $5 \mathrm{~mm}$ in thickness. The dried green body was sintered stepwisely with $200{ }^{\circ} \mathrm{C}$ for 2 hours and $850{ }^{\circ} \mathrm{C}$ for 2 hours.

\section{Measurement of Porosity and Pore Size Distribution}

Porosity of sintered body was measured by Archimedes method. Air in pore was vacuumed under low pressure of 2.0 $\mathrm{kPa}$ and the pore was filled with water. Porosity was calculated from the difference of weight between the wet body and dried one.

Pore size distribution is measured by a mercury penetration method using a mercury porosity meter in other reports. However, in this study, a lot of ceramics samples with different condition were prepared. The measurements for all the samples with a mercury porosity meter would produce a lot of waste containing mercury. In addition, mercury porosity meter is not common facility especially in developing countries. Considering the reduction of the waste containing mercury and alternative method that is available even under the limited conditions for facilities, the estimation of pore size distribution from Scanning Electron Microscope (SEM) images was designed. SEM is not simple system but it can be found as one of basic facilities for general purposes even in developing countries.

The image taken with low magnification ratio (40-50 magnification) can observe $10-100 \mu \mathrm{m}$. Firstly, the pores on the image were counted and total area of the pores on the image was found by image analysis. It was assumed that all the pores are spherical shape and the characteristic pore diameter in the image was calculate from the number of pores and the total area in the image.

$$
\mathrm{D}=2 \sqrt{\frac{\sum A}{\pi N}}
$$

where $D$ is characteristic diameter in the image, $\Sigma \mathrm{A}$ is the total area of the pores in the image, $\mathrm{N}$ is number of pores in the image.

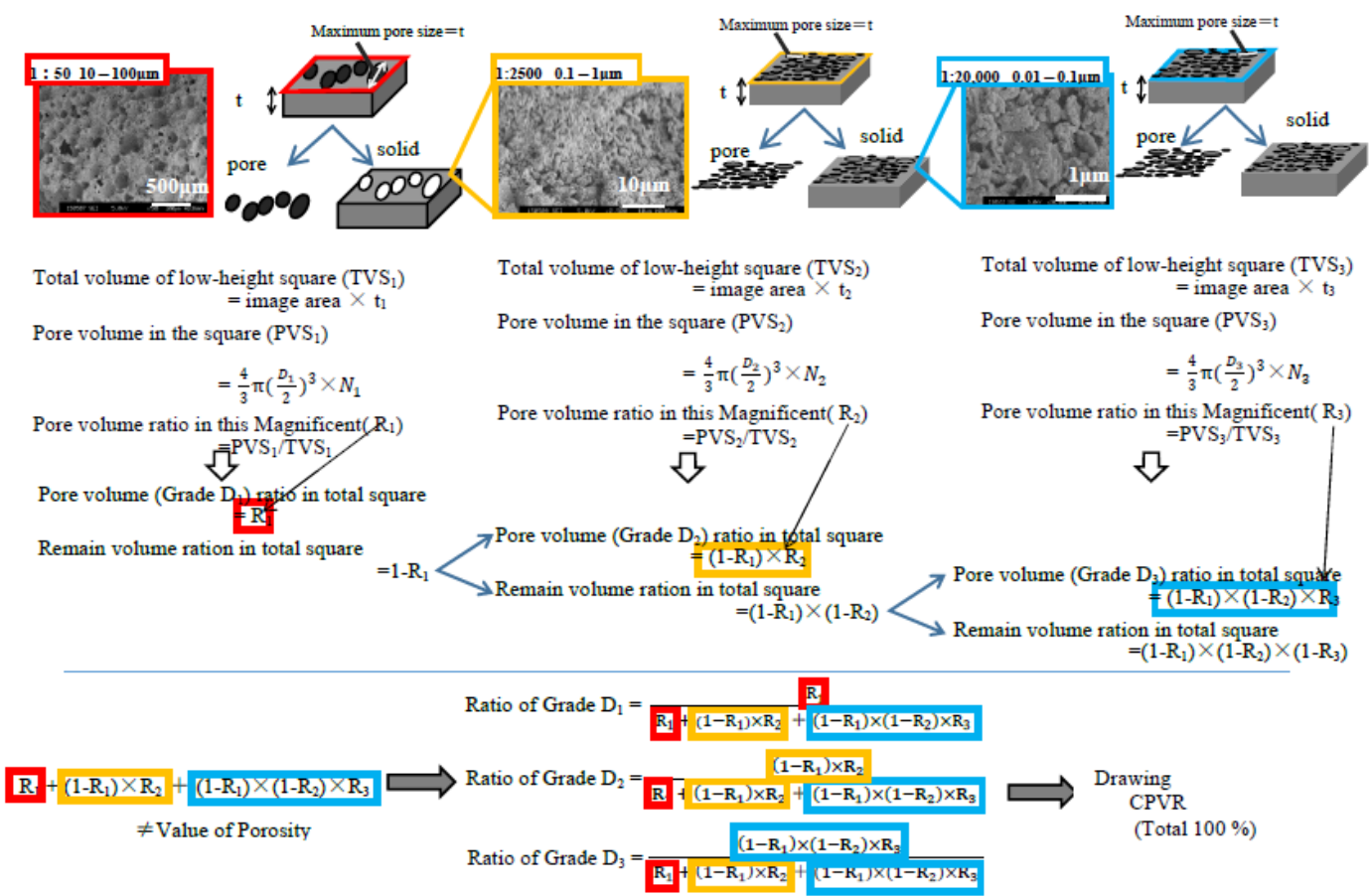

Fig. 3. Estimation of pore size distribution from SEM images.

On the hand, the maximum diameter among the pores in the image was considered as the characteristic thickness $(\mathrm{t})$ (Fig. 3). It was assumed that the volume of the square that is $t$ in depth with whole the image area was partially occupied by the volume of pores observed. Then, the volume ratio of the pores in the square was calculated.

Remaining solid part was observed with higher magnification. As same as above procedure, characteristic 
diameter and pore volume ration can be calculated in the higher magnification image. These procedures were carried out with the middle (2500) magnification image for observing pore diameter of $0.1-1 \mu \mathrm{m}$ and high $(20,000)$ magnification image for $0.01-0.1 \mu \mathrm{m}$. From the calculated characteristic diameters and pore volume ratios from the different magnification images, subtotal pore volume in each magnificent image was estimated. Summation of the subtotal volume should be equal to the porosity of the ceramics, but those are not equivalent due to errors in this visual method with SEM. Therefore, we respect the ratio of the volume of each pore size grade, total of that is $100 \%$.

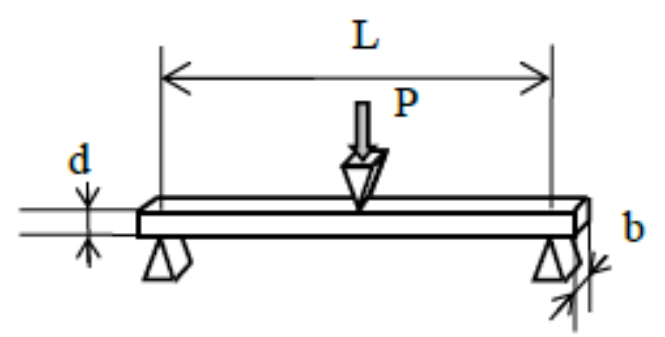

Fig. 4. Three point bending flexural test.

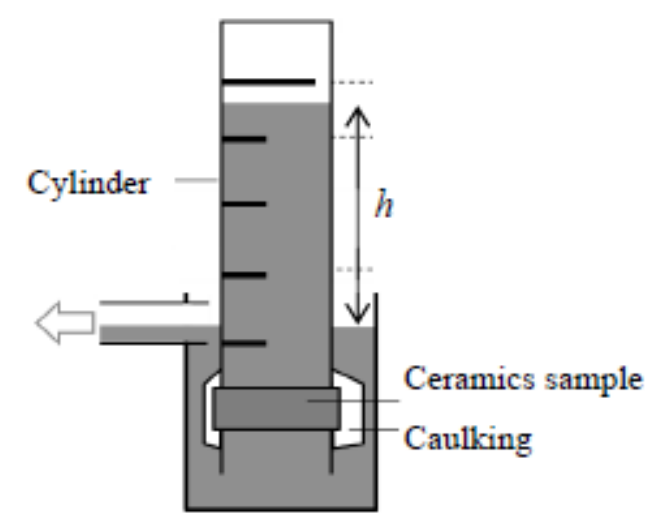

Fig. 5. Falling head permeability test.

\section{Strength Evaluation by Bending Test}

The three point bending flexural test provides values for the modulus of elasticity in bending. Fig. 4 is the diagram of the test. Load $(\mathrm{P})$ was gradually increased until the fracture of the test piece and the load and the strain were measured every 0.01 second. The flexural stress was calculated as shown below.

$$
\sigma_{f}=\frac{3 P L}{2 b d^{2}}
$$

where $\sigma_{f}$ is Tensile stress in outer surface at midpoint (MPa), $\mathrm{P}$ is load at a given point on the load deflection curve $(\mathrm{N}), \mathrm{L}$ is Support span: $30(\mathrm{~mm}), \mathrm{b}$ is Width of test piece $(\mathrm{mm}), \mathrm{d}$ is Depth of tested piece $(\mathrm{mm})$.

The test pieces $(\mathrm{L}=40 \mathrm{~mm}, \mathrm{~b} \& \mathrm{~d}=5 \mathrm{~mm})$ are carved from the sintered ceramics samples that have $40-43 \mathrm{~mm}$ of diameter and 7-8 $\mathrm{mm}$ of thickness as original size.

\section{E. Permeability}

Permeability of porous ceramics define the treatment capacity as a filter. It was evaluated by falling head permeability test. Thin cylinder $(\varphi 29 \mathrm{~mm}, 10 \mathrm{~cm})$ was attached with the ceramics samples and its surface except the examined part was caulked as shown in Fig. 5. The ceramics samples with the cylinder was dipped in water for 48 hour air in water before the examination in order to remove the air in pore. The water level lowering time from $\mathrm{h}_{0}$ to $\mathrm{h}$ was measure and permeability was calculated with below equation.

$$
\mathrm{k}=\frac{L}{t} \ln \frac{h_{0}}{h}
$$

where $L$ is length of specimen, $\mathrm{h}_{0}$ is initial water head, $\mathrm{t}$ is lowering time from $h_{0}$ to $h$. the measurements were carried out with room temperature $\left(18^{\circ} \mathrm{C}\right)$

\section{RESUlTS AND DISCUSSION}

\section{A. Drying and Sintering Process to Avoid Cracking}

As mentioned in the previous chapter, rapid drying that makes uneven water content distribution causes cracking. By controlling the surrounding condition, occurrence of cracking in drying process could be reduced. On the other hand, when moving to sintering process, the excess water remain in a green body causes cracking too. In the box with small holes for controlling drying ratio, there is a difference of condition in microscale. Although ceramic samples are placed in the box for same duration, samples with/without cracks, both were found in sintering process. The progress of drying have to be evaluated not by the drying time, but by the weight of green body.

In this study, 240 wet-green body by the gelcasting process were prepared. In order to check the critical moisture content that does not make cracking in sintering process, wet-green body samples were weighed, then sintered in order. Fig. 6 shows the change of occurrence of cracks in sintering process, depending on the water content of the green bodies. As a result, cracks do not occur with less than $35 \%$ of moisture content before sintering. This critical value of moisture content might be a standard for designing the production process of porous filter with sediment that has high shrinkage rate.

\section{B. Relationship between Preparation Process and Pore Characteristics}

Fig. 7 and 8 shows the variation of porosity of the sintered body depending on the change of the processes. With the increase of the initial water content, the porosity showed higher value. It was supposed that there are 2 reasons for that variation. First, higher water content in slurry results in filling the volume with the lower density of ceramics material particles and the pores between particles were produce by evaporation of pore water in slurry. Generally, regardless of frothing-up, this tendency of porosity variation with the initial water content is found. Higher water content changes other parameters such as shrinkage rate in the process from drying to sintering and strength. It gives negative influence on these parameters due to structural defects that would be discussed with SEM images and bending flexure test in the following chapters. Second reason is improvement of liquidity of slurry due to adequate water content for frothing-up.

Mixing time is one of the factors to vary the porosity. In the cases of initial water content of $70 \%$ and $90 \%$ in Fig. 7 , the increase of porosity depending on the mixing time was 
clearly found. The growth of porosity in the cases of initial water contents of $100 \%$ reached the ceiling even though mixing time or surfactant amount is increased. It was supposed that the ceramics can not keep its structure with so low density of the particles. The maximum porosity controlled by the proposed procedure with mixing time, initial water content and surfactant was 75-80\%.

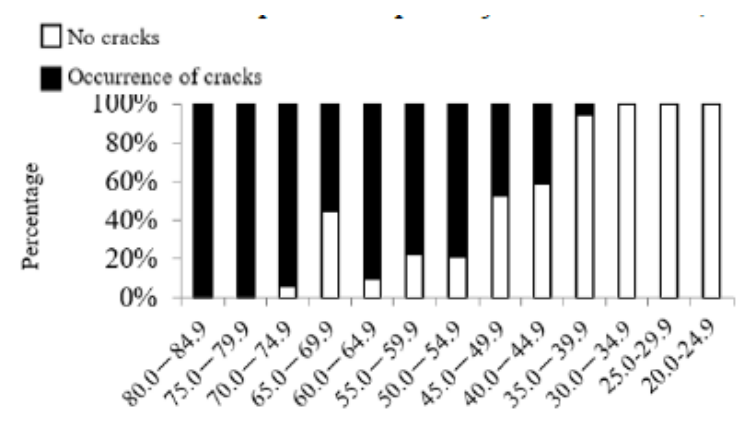

Fig. 6. Moisture content before sintering to prevent cracking.

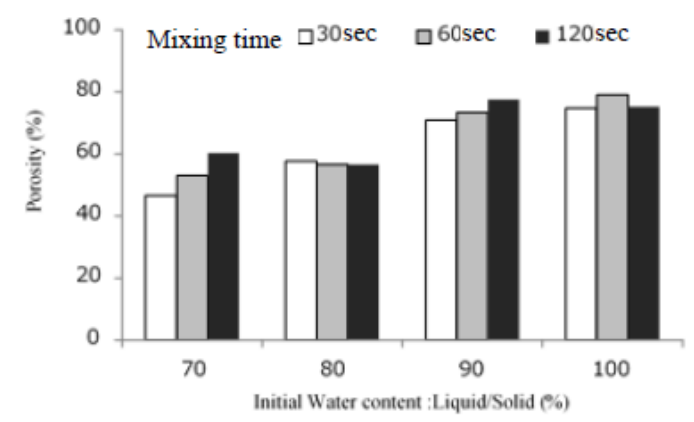

Fig. 7. Variation of porosity depending on initial water content and Mixing time (amount of surfactant was common at $1 \mathrm{wt} \%$ of total weight).

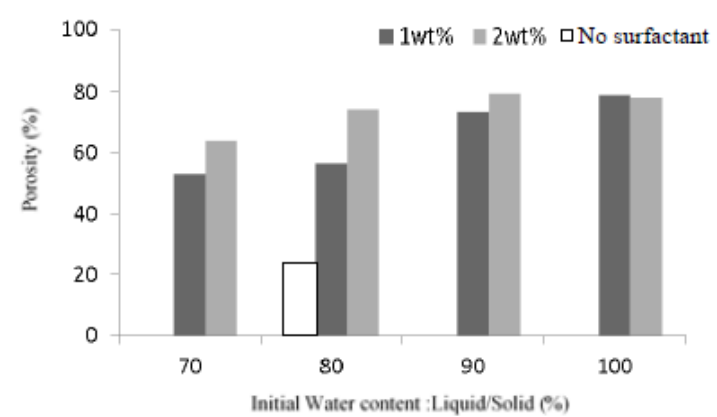

Fig. 8. Variation of porosity depending on initial water content and Surfactant amount (Mixing time was common at 60 seconds).

Before the discussion about the pore size distribution, the accuracy evaluation of the method proposed in this study is required. Fig. 9 shows the comparison of the curves of Cumulative Pore Volume Ratio(CPVR) about 4 cases with the different preparation, estimated with the different 2 methods. The blue line is measured by mercury porosity meter, while red one is estimated by SEM image analysis as proposed. Comparison of the values of D20, D50 and D80 (Pore size at that the cumulative curve exceed 20, 50, $80 \%$ ) in the 4 graphics, estimated by the 2 methods are plotted in Fig. 10. The 2 results do not show perfect agreement but it can indicate the tendency of the distributions. The following discussion was described with the result estimated with the proposed method.

Fig. 11 shows the variation of the cumulative porosity curve with the different preparation cases. Cumulative porosity shown in vertical axis is the different value from
CPVR in Fig. 9. End of Cumulative porosity (right end of the curves in Fig. 11) is equal to the total porosity of each ceramics sample while that of CPVR is $100 \%$. Cumulative porosity is the value of that total porosity multiplied with CPVR. Fig. 11 (a) is the comparison of the cases that have same frothing time but different water contents. The cases that have longer frothing time were shown in Fig. 11 (b). Horizontal black dash lines in both of the figures are the porosity of the ceramics prepared without surfactant and frothing $(23.8 \%)$. Pores increased by surfactant and frothing have diameter of more than $10-100 \mu \mathrm{m}$ while smaller pore distributions were almost same in any cases. The cumulative pore volume ratios of the small pore were around the porosity of the ceramics without surfactant and frothing. The smaller pores were produced by evaporation of pore water in slurry, not by frothing. As one of the ways to produce pores, surfactant template method was proposed in previous studies. Micelle of added surfactant was formed before molding and that was remove in sintering process. The pores produced by this method was very fine [26]. In this study, added amount of surfactant is so little that surfactant molecular does not affect the pore size distribution significantly, though surfactant was added. That is the reason why the pores smaller than $10 \mu \mathrm{m}$ was not produced so much even with surfactant.

\section{Strength Evaluation}

The average strength (Flexure strength in outer surface at midpoint in the 3 points flexure test) of the sintered body is plotted against the porosity of the sintered body in Fig. 12.

The strength of the ceramics made from sediment without frothing, evaluated in our previous study, was $12.37 \mathrm{MPa}$ [14]. Comparing with that, the strength of the porous ceramics in this study was generally lower. That is due to the occupation of pores replacing ceramic material. Because of the same reason, the average strength tended to decrease with the increase of the porosity. That tendency was found in the other studies that processed other ceramic material with natural polymers [27].

As mentioned in the previous chapter, number of the larger sized pore could be increased by controlling initial water content or frothing time. The influence of these factors of controlling porosity on the strength was evaluated in Fig. 12. Seeing the strength variation from the case with $70 \%$ of initial water content and 30 seconds of frothing time as a reference, both of the cases that change water content to $90 \%$ and frothing time to 120 seconds respectively reduce the strength. The strength with the frothing time of 120 seconds shows higher strength than the case that changes water content to $90 \%$ but both of the reduction rate of strength depending on porosity increase (shown as the gradient in Fig. 12 ) is almost same. Fig. 13 is the SEM images of the three cases. The image of the lowest porosity case ((i)Water Content $70 \%$, Frothing 30 seconds) shows low porosity visually in the image while the other 2 images shows a lot of pores in the images. Comparing between (ii) and (iii), due to the difference of porosity, (ii) looks hollower but morphological characteristics is similar, spherical shape of pores, connecting pores network etc. This morphological similarity might cause that the reduction rates of strength depending on porosity increase were almost same even with 
the different way of increasing the number of pores.

From the view point of industrial process, if same porosity and same strength are obtained by the change of initial water

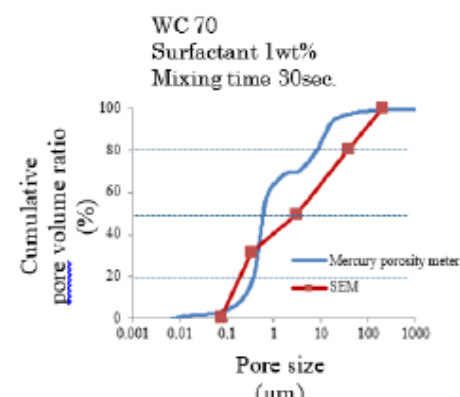

$(\mu \mathrm{m})$

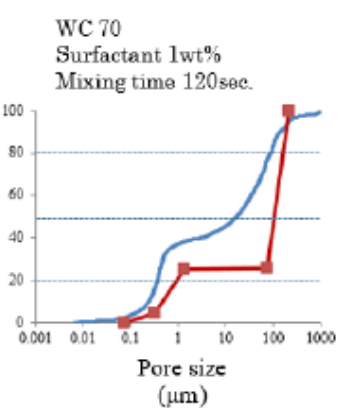

Fig. 9. Comparison of cumulative curves of pore size estimated with the different 2 methods for the 4 cases. content or frothing time, the porosity have to be controlled by frothing time. Higher water content needs longer drying time that would cause inefficient productivity.

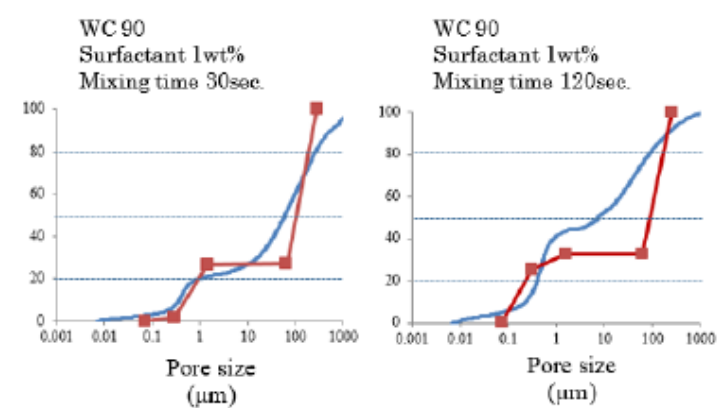

\section{Permeability}

The permeability of the sintered body is plotted against the porosity of the sintered body in Fig. 14. The permeability tended to increases with the increase of porosity. Higher porosity gives much water path. Kozeny's equation is used in the field of fluid dynamics to calculate the pressure drop of a fluid flowing through a packed bed of solids [28].

$$
k=\mathbf{c} \frac{\lambda^{3} d^{2}}{(1-\lambda)^{2}} \frac{\rho g}{\mu}
$$

where $\mathrm{k}$ is permeability coefficient $(\mathrm{m} / \mathrm{sec}), \lambda$ is porosity $(\%), \mathrm{d}$ is diameter of solid particle $(\mathrm{m}), \rho$ is density of fluid $\left(\mathrm{kg} / \mathrm{m}^{3}\right), \mathrm{g}$ is gravity acceleration, $\mu$ is viscosity of fluid $(\mathrm{Pa} \cdot \mathrm{s})$. This equation can estimate permeability coefficient of bulk of particles such as sand. On the other hand, the porous ceramics are the sintered body. Therefore, it is impossible to apply this equation directly to the result of this study. The diameter of solid particle (d) in the equation is not the diameter of the sediment particle. The known parameter in this study is range of the diameter of pores. The dominant pores produced by frothing was $10-100 \mu \mathrm{m}$. Generally, the pore diameter is approximately $1 / 10$ of solid particle diameter. As a reference, the relationship between permeability coefficient and porosity was calculated with Kozeny's equation substituting 10 times value of pore size for the solid particle diameter. The estimated relations between permeability coefficient and porosity were shown as lines in Fig. 14. The experimental result shown as triangle markers are that of the ceramics whose dominant pores are $100 \mu \mathrm{m}$ while rectangular markers indicate that with $10 \mu \mathrm{m}$ order pore size.

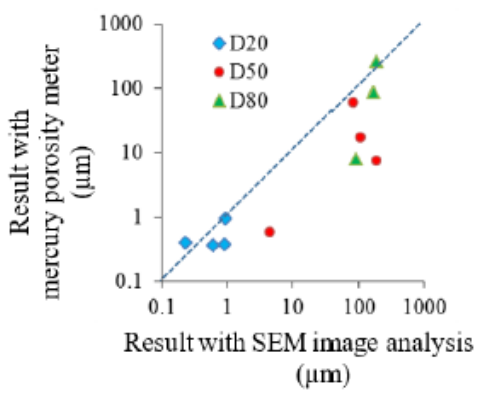

Fig. 10. Comparison of D20, D50 and D80 of the 4 cases, estimated by two different methods.

The difference from the experimental result is due to the density of water path. The permeability estimated by
Kozeny's equation is based on the assumption that pores are distributed evenly between solid particles. On the other hand, the pathways on the porous ceramics were limited. It is difficult to estimate permeability of porous ceramics with the equation. However, seeing the high correlation between observed porosity and permeability coefficient, permeability of porous ceramics made from sediment can be controlled by the process, as same as porosity, with the range from $10^{-5}$ to $10^{-1}$ order.
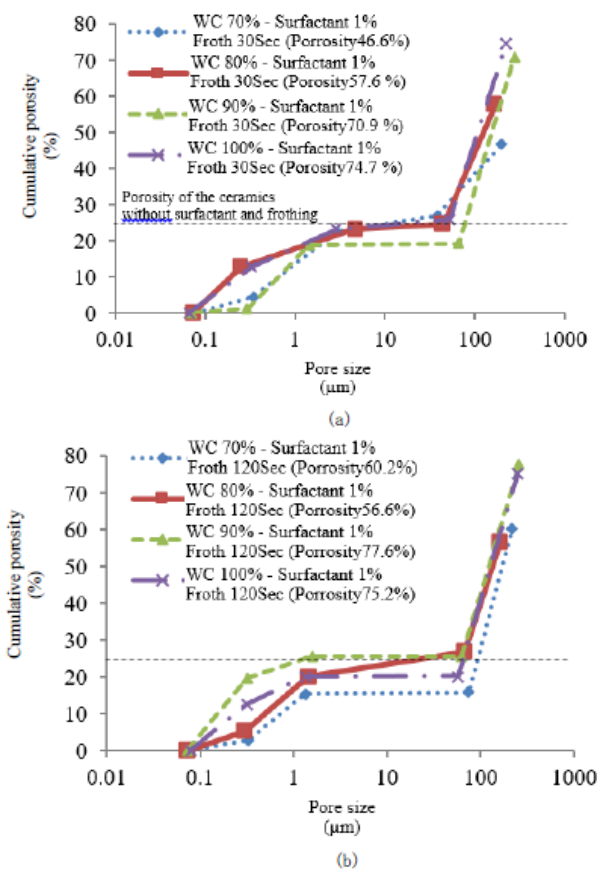

Fig. 11. Variation of the cumulative pore volume ratio curves with different preparation cases

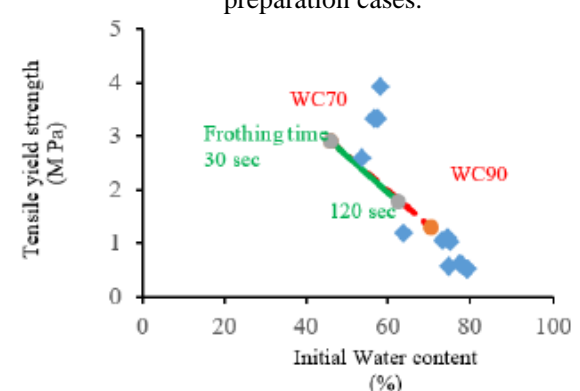

Fig. 12. Relationship between initial water content and result of the flexure test.

\section{E. Production Cost Evaluation}


The motivation of this study is covering the dredging cost of reservoirs. Therefore, processing cost and profitability evaluation is indispensable. In this study, the processing cost and selling price of porous ceramics is compared with that of construction brick consisting of simple ceramics. The cost and price of construction bricks were investigated in Tunisian Dinar [14]. Those values were converted to that in US Dollar in accordance with information about a current currency exchange rate. Regarding the process cost of porous filter, basic process was same as that of construction brick except frothing. In this estimation, the additional material costs of resin and initiator were counted. As shown in Fig. 15, large part of the processing cost of porous filter was occupied by the price of resin and initiator. The selling price of porous filter was estimated from the price of similar product marketed in Japan. The inquiring survey with a ceramics filter company was carried out. The price of a small piece of filter $(\varphi 40 \mathrm{~mm} * 10 \mathrm{~mm})$ that has similar property as ceramics filter was around 300 Japanese Yen. Considering the market where we want to sell, consumer might be in Tunisia or other surrounding developing country. As a primary estimation, $1 / 3$ of the price of the commercial ceramics filter was set as that of porous filter produced in this study and the price was converted to US dollar.
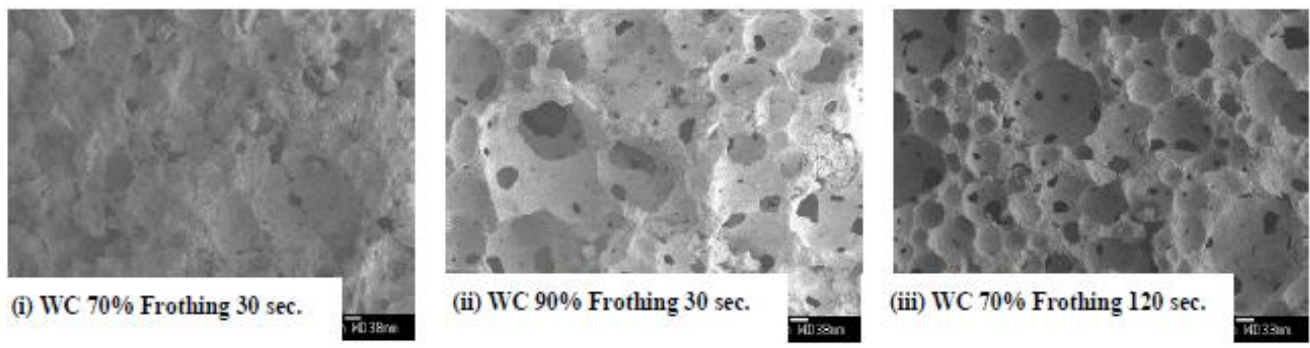

Fig. 13. SEM images of the 3 ceramics samples.

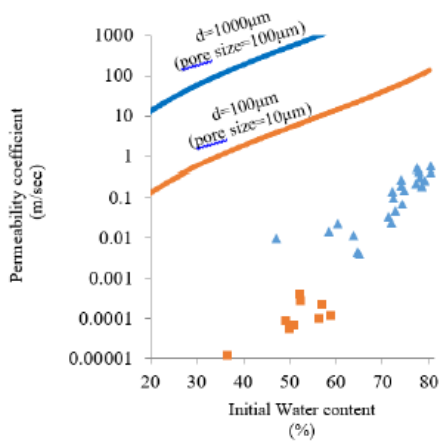

Fig. 14 Relationship between initial water content and permeability coefficient.

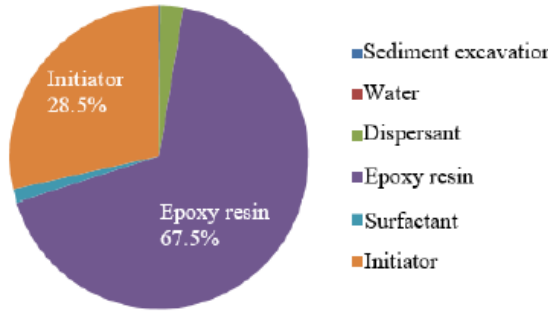

Fig. 15. Share of the material cost of porous ceramics filter.

TABLE III: EVALUATION OF BALANCE BETWEEN PRODUCTION COST AND SELLING PRICE

\begin{tabular}{|c|c|c|}
\hline & Brick [14] & $\begin{array}{l}\text { Porous filter } \\
\left(\phi 40 \mathrm{~mm}^{*} 10 \mathrm{~mm}\right)\end{array}$ \\
\hline Processing Cost & $0.27 \mathrm{USD} /$ piece & $0.07 \mathrm{USD} /$ piece \\
\hline Selling price & $0.36 \mathrm{USD} /$ piece & $0.86 \mathrm{USD} / \mathrm{piece}$ \\
\hline (Price-Cost) / Cost & 1.28 & 12.1 \\
\hline $\begin{array}{l}\text { Number of products } \\
\text { from sediment of } 1 \mathrm{~m}^{3}\end{array}$ & 100 piece & 90,000 piece \\
\hline
\end{tabular}

Based on these assumptions, processing cost and selling price were compared between construction brick and porous filter (Table III). Finally, the profit ration against processing cost of the porous ceramics was 10 times than that of construction brick. The cost per piece of brick was more expensive than that of porous filter because of the difference of size of a piece. Brick production consumes much volume of sediment than the small porous filter (approx. 900 times). Considering this difference, the production cost of porous ceramics looks expensive. However, seeing the balance with selling price, even discounting form the price of similar products in Japan, added value as shown in the value of (Price-Cost) / Cost was much more.

Comparing with the market of brick in Tunisia, where all the buildings are constructed with bricks, the market of porous filter is limited currently in this country. The filter with $10-100 \mu \mathrm{m}$ pores, produced in this study is applicable for polymer separation in textile industry, separation of sludge in fermentation industry, waste water treatment etc. [29]. The contribution of the porous filter to the development of such industries and environmental management will be expected in the future. One of the contributions of this study is proposing alternative use of sediment. Those multi-use will consume the sediment totally and cover the dredging cost. In addition, large part of the processing cost of porous filter was epoxy resin and initiator. For this expensive fixation agent, natural polymers such as agar and gelatin can be substituted [27]. In this trial study, the fixation with epoxy resin, that is most easy process to handle, was applied. In further study, from the point of view of cost reduction, the use of natural polymer or other cheaper fixation agent will be discussed.

\section{CONCLUSIONS}

Porous filter could be made from sediment in reservoir by gelcasting method. Its porosity could be controlled by the producing process. Higher water content and longer mixing time give higher porosity. Depending on the increase of porosity, its strength decreases and permeability decreases. Maximum porosity was around $80 \%$. The result of pore size distribution analysis shows that the pores produced by frothing surfactant was 10-100 $\mu \mathrm{m}$. 
As a result of evaluation of profitability, the added value was significantly higher than the value of construction brick that was proposed as exploitation of sediment in reservoir in previous study. It still needs the improvement of the process of gelcasting for the reduction of production cost and the market development of the ceramics filter.

\section{REFERENCES}

[1] B. Remini, "La sédimentation dans les barrages de l'Afrique du Nord," Courrier du Savoir, vol. 4, pp. 65-69, 2003.

[2] M. Irie, A. Kawachi, J. Tarhouni, and A. Ghrabi, "Development of sedimentation and characteristics of sediment on the reservoir in Tunisia," Journal of Japan Society of Civil Engineering, Ser. B1, vol. 67, no. 4, pp. 163-168, 2011.

[3] S. Kantoush, T. Sumi, and M. Murasaki, "Evaluation of sediment bypass efficiency by flow field and sediment concentration monitoring techniques," Journal of Japan Society of Civil Engineering, Ser. B1, vol. 67, no. 4, pp.169-174, 2011.

[4] T. Sumi, S. Kantoush, and S. Suzuki, "Performance of miwa dam sediment bypass tunnel: Evaluation of upstream and downstream state and bypassing efficiency," International Commission on Large Dams, 24th Congress, Kyoto, Q92-R38, p. 576, 2012.

[5] M. Shintake and M. Irie, "Dam gate operation for turbid flood water venting in the reservoir in Tunisia," Journal of Arid Land Studies, vol. 25, no. 3, pp. 149-152, 2015.

[6] T. Ishikawa, M. Wang, and M. Irie, "Numerical study on the process of sedimentation in Joumine Reservoi, Tunisia," Journal of Japan Society of Dam Engineering, vol. 25, no. 1, pp. 29-37, 2015.

[7] M. Irie, A. Kawachi, I. Nsiri, and J. Tarhouni, "Observation of floodwater behavior and sedimentation in the reservoir," Journal of Japan Society of Civil Engineering, vol. 69, no. 4, pp. 247-252, 2013.

[8] M. Oya, T. Sumi, and M. Kamon, "Cost analysis and feasibility study for pfi project on dam sediment recycling," Journal of Japan Society of Dam Engineers, vol. 13, no. 2, pp. 90-106, 2003.

[9] K. Sato, T. Fujikawa, H. Tanaka, and S. Yokot, "Repairing material for embankment using a bottom sludge of age-old reservoir," Journal of the Society of Materials Science, vol. 59, no. 1, pp. 50-55, 2010.

[10] S. Mtibaa, M. Irie, M. Ksibi, H. Trabelsi, O. Hentati, M. Kallel, and H. Isoda, "Soil amendment by sediment from water storage reservoir as a restoration technique in secondary treated wastewater irrigated area at El Hajeb region," Journal of Arid Land Studies, vol. 22, no. 1, pp. 315-318, 2012

[11] A. Kawachi, P. Yamada, M. Irie, and H. Isoda, "Characterization of humic substances in sediment on Joumine reservoir in Tunisia," Journal of Arid Land Studies, vol. 22, no. 1, pp. 49-52, 2012.

[12] M. Irie, J. Han, A. Kawachi, J. Tarhouni, M. Ksibi, K. Kashiwagi, and H. Isoda "In vitro testing and commercialization potential of extracted fulvic acid from dredged sediment from arid region reservoirs," Waste and Biomass Valorization, vol. 5, pp. 273-281, 2014.

[13] I. Haouas and M. Yagoubi, "Trade liberalization and labor-demand elasticities: Empirical evidence from Tunisia," IZA Discussion paper, 1084, 2004.

[14] M. Irie, K.Kashiwagi, K. Ujiie, I. Nsiri, S. Bouguerra, and J. Tarhouni, "Feasibility of exploitation of the sediment in the reservoirs for the sustainability of surface water resource in Tunisia," Journal of Japan Society of Civil Engineering, Ser. G, vol. 68, no. 6, pp. II41-46, 2012.

[15] M. Irie and J. Tarhouni, "Water reservoir as resource of raw material for ceramic industry," Journal of Physics, 2015.

[16] M. Hung and C. Hwang "Study of fine sediments for making light weight aggregate," Waste Management Research, vol. 25, pp. 449-456, 2007.

[17] K. Chiang, K. Chien, and S. Hwang "Study on the characteristics of building bricks produced from reservoir sediment," Journal of Hazardous Materials, vol. 159, pp. 499-504, 2008.
[18] M. Samara, Z. Lafhaj, and C. Chapiseau, "Valorization of stabilized river sediments in fired clay bricks: Factory scale experiment," Journal of Hazardous Materials, vol. 163, pp. 701-710, 2008.

[19] Japan International Cooperation Agency, "The study on integrated basin management focused on flood control in Mejerda River in the Republic of Tunisia: Interim report," p. 25, 2007.

[20] T. Hata and M. Irie, "Feasibility study of the Ichkeul lake environmental remediation technology by using the Joumine water reservoir sediments," Journal of Japan Society of Civil Engineering, Ser. G, vol. 71, no. 4, pp. 125-133

[21] M. S. Laurel, "Porous materials," The American Ceramic Society, Ceramic Transactions, vol. 31, pp. 3-23, 1992.

[22] S. Kwon, G. Son, J. Suh, and K. T. Kim, " Densification and grain growth of porous alumina compacts," Journal of American Ceramics Society, vol. 77, no. 12, pp. 3137-3141, 1994

[23] S. Geis, J. Fricke, and P. Löbmann, "Electrical properties of PZT aerogels," Journal of European Ceramics Society, vol. 22, no. 7, pp.1155-1161, 2002.

[24] H. X. Peng, Z. Fan, J. R. G. Evans, and J. J. C. Busfield, "Microstructure of ceramic foams," Journal of European Ceramics Society, vol. 20, no. 7, pp. 807-813, 2000.

[25] S. Izuhara, K. Kawasumi, M. Yasuda, H. Suzuki, and M. Takahashi, "Highly Porous Cordierite Ceramics Fabricated by in situ Solidification Technique, Ceramic Processing Science VI," Ceramic Transactions, vol. 112, pp. 553-558, 2000.

[26] B. Melde, B. Johnson, and P. Charles, "Mesoporous silicate materials in sensing," Sensors, vol. 8, pp. 5202-5228, 2008.

[27] K. Jono, M. Fuji, and M. Takahashi, "Porous ceramics for building material fabricated by in situ solidification method using natural polymer and waste resource," Journal of the ceramics society of Japan, Supplement vol. 112-1, no. 5, pp. S138-S143, 2004.

[28] J. Kozeny, "Ueber kapillare Leitung des Wassers im Boden," Sitzungsber Akad. Wiss., Wien, vol. 136, no. 2a, pp. 271-306, 1927.

[29] K. Matsumoto, "Ceramics filter for liquid separation," Journal of the Society of Inorganic Materials, Japan, vol. 12, pp. 478-485, 2005.

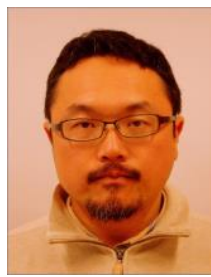

Mitsuteru Irie is a full professor in environmental hydraulics at Faculty of Engineering, University of Miyazaki, Japan.

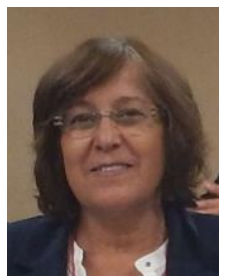

Jamila Tarhouni is a full professor in water resource management at National Institute of Agronomy Tunis.

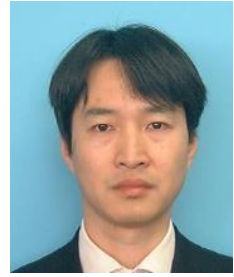

Masayoshi Fuji is a full professor in material science at Advanced Ceramics Research Center, Nagoya Institute of Technology. 